\title{
Congenital heart disease in 2018
}

Clara Vázquez-Antona, ${ }^{1}$ Carlos Alva-Espinosa, ${ }^{2}$ Lucelli Yáñez-Gutierrez ${ }^{3}$ and Horacio Márquez-González ${ }^{3}$ ${ }^{1}$ Secretaría de Salud, Instituto Nacional de Cardiología, Department of Echocardiography; ${ }^{2}$ Hospital Ángeles del Pedregral; ${ }^{3}$ Instituto Mexicano del Seguro Social, Centro Médico Nacional Siglo XXI, Cardiology Hospital, Ciudad de México, Mexico

\begin{abstract}
We present an update of the most relevant advances of three-dimensional echocardiography for the diagnosis of congenital heart diseases. The evolution of its treatment is analyzed, showing the results obtained in recent years. The functional and structural changes experienced in women with congenital heart disease during pregnancy are discussed, as well as the main health risks and the importance of teamwork in healthcare to treat these patients. Finally, we provide a review on the current situation in Mexico and outline some improvement recommendations.
\end{abstract}

KEY WORDS: Congenital heart disease. Echocardiographic diagnosis. Pregnancy.

Gac Med Mex. 2018;154:598-611

Contents available at PubMed www.gacetamedicademexico.com 


\title{
Three-dimensional echocardiography in congenital heart diseases
}

\author{
Clara Vázquez-Antona
}

The complex anatomy and the sophisticated functioning mechanisms of cardiac structures in patients with congenital heart disease (CHD) require for the use of echocardiographic techniques as a diagnostic method to cover two basic aspects: morphology and function. Two-dimensional (2D-Echo) and Doppler echocardiography it is up to this moment a useful diagnostic tool and in many cases sufficient for morphological and hemodynamic evaluation. One of the limitations of $2 \mathrm{D}$-Echo lies in that it is done in a single plane, and acquisition of images with different approaches is therefore required, which forces for a mental reconstruction to be carried out to better understanding them.

Three-dimensional echocardiography (3D-Echo) assesses the heart at its three dimensions, either in a view as a whole or with conventional and unconventional planes. The benefit of three-dimensional (3D) reconstruction of the heart with congenital defects lies in the potential to objectively show the anatomy and the complex relationships between different cardiac structures, achieving images oriented in an unlimited way such as the "surface" views of the atrioventricular (AV) and ventriculoarterial valves, as well as the interatrial and interventricular septum, in addition to the assessment of left and right ventricular function and univentricular physiology heart conditions. ${ }^{1}$ Unlike 3D reconstruction in acquired heart disease, patients with complex $\mathrm{CHD}$ may have alterations in the position, situs, connections and relationships of structures of the heart, which implies a greater challenge than in patients with acquired pathology.

The use of 3D-Echo for CHD routine study requires a learning curve and demands specific training, since in addition to knowledge about CHD and its treatment, the training should include acquisition and post-processing of $3 \mathrm{D}$ data in order to demonstrate the competence in morphological evaluation and cardiac function quantification. ${ }^{2,3}$ Recognizing and assessing the views of the heart that are feasible with 3D, including views of the valves and septa, should be learnt.

\section{Background}

Dekker et al. initiated three-dimensional cardiac imaging in 1974 using a "hands-free" articulated mechanical arm to obtain transthoracic images for subsequent processing. In 1993, Pandian and Roelandt introduced dynamic 3D-Echo with multi-planar transesophageal transducer, where reconstruction started from the acquisition of two-dimensional planar images obtained in synchrony with the cardiac cycle and respiratory movements, which were stored in an independent database. In the early 1990s, von Ramm et al. ${ }^{4}$ developed the first real-time three-dimensional echocardiographic equipment, which has had improvements in design and engineering up to the types of equipment that we currently use both for transthoracic and transesophageal approaches.

In Mexico, the experience with 3D-Echo was initiated at the Echocardiography Department of the National Institute of Cardiology "Dr. Ignacio Chávez" in 1999 with off-line 3D-Echo by Vargas-Barrón et al. ${ }^{5}$ In 2002 , the results of the first 54 patients with CHD who underwent $3 \mathrm{D}$ reconstruction from sequential transesophageal two-dimensional images with post-processing were reported. In this initial experience, bi- and three-dimensional images were compared and correlated with equivalent anatomical specimens to assess their correspondence.

By then, 3D reconstruction of heart diseases was shown to be possible in all cases, confirming that it defined anatomical details additional to those obtained by 2D, since reconstructions from unconventional views were achieved, such as those observed from the atria or atrioventricular connections' apexes, as well as both interatrial and interventricular septum surface views; even when acquisitions were time-consuming, images that provided valuable additional information were obtained. ${ }^{6}$

In 2005, the experience with real-time 3D transthoracic echocardiography was initiated, which is a method that was easily applied to pediatric patients, since the acoustic windows are favorable, and morphological information is indispensable for the understanding of $\mathrm{CHD} ;{ }^{7}$ in 2011, real-time transesophageal 3D-Echo started being used. Currently, most echocardiography laboratories of centers that manage patients with $\mathrm{CHD}$ have integrated this technology as a complementary diagnostic method. 


\section{Clinical applications of three-dimensional echocardiography}

The clinical application of 3D reconstruction of the heart with congenital defects covers mainly 3 areas: morphology visualization, volumetric quantification of cardiac chambers and fluxes and guidance in trans-catheterization invasive procedures and intraoperative assessment. Real-time 3D reconstruction is possible with transthoracic and transesophageal (TEE) echocardiographic approaches.The limitation of 3D TEE is that the probe can only be used in patients with more than $20 \mathrm{~kg}$ of weight. Data acquisition of can be in two forms:

1. Real-time "live 3D" using simultaneous multi-planar imaging, which shows two-dimensional images in two simultaneous orthogonal planes, real-time $3 D$ mode and $3 D$ amplification or $3 D$ zoom.

2. Multi-heartbeat, coordinated with electrocardiogram, where full volumes or wide angle and full volume with color Doppler can be obtained for post-processing.

3D-Echo contributions can be stratified in 3 groups:

1. Information equivalent to that of studies with 2D-Echo.

2. New findings not seen on 2D-Echo, but that do not critically modify therapeutic decision making.

3. Additional anatomical information that is useful in therapeutic decision making.

The two first groups allow a better understanding of the anatomy with "pleasant" images and interesting anatomical perspectives and are more useful from the academic rather than the therapeutic point of view and helpful to improve communication with clinicians and surgeons

The third group provides greater clinical benefit, as determined by the ability to define defects from atrial, ventricular and valvular surface views with additional information that is useful for therapeutic decisions. This group includes images obtained in heart diseases with complex forms of atrial and ventricular septal defects, common atrioventricular canal (Fig. 1), mitral valve (VM) congenital anomalies and alterations of the arterial ventricular coupling, such as right ventricle double chamber outlet, as well as left ventricular function in heart diseases where the left ventricle has lost its geometry. Approximately $35 \%$ of studies correspond to the latter group. ${ }^{8}$

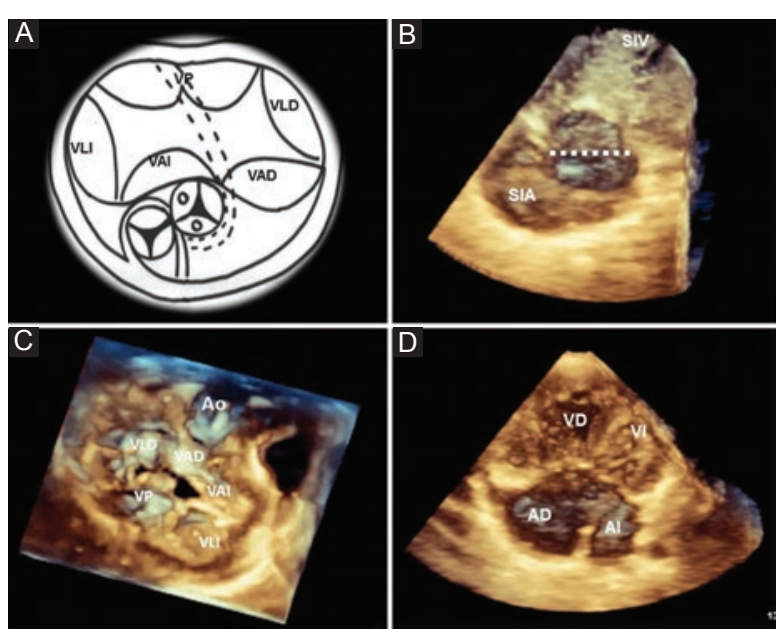

Figure 1. Three-dimensional reconstruction transthoracic images of a patient with a common atrioventricular canal and diagram $(A)$. Unconventional views from the left septal view (B), atrial surface view $(C)$ and view of four chambers are shown, where the common atrioventricular valve and atrial and ventricular septal defects are observed (D). In $B$, we observe the ventricular and atrial defects of the ostium primum "en face" type; the dotted line marks at the AV septum level, in this case absent. In $C$, the five valves with their right and left valvular components and the anterior and posterior bridge valves and their correspondence with the diagram in $A$ are observed. $V A I=$ anterior left leaflet, $V L I=$ left lateral leaflet, $V P=$ posterior leaflet, $V L D=$ right lateral leaflet, $V A D=$ right anterior leaflet, $A O=$ aorta, $V D=$ right ventricle, $V I=$ left ventricle, $A D=$ right atrium, $S I V=$ interventricular septum, $S I A=$ interatrial septum.

Recently, a consensus document ${ }^{9}$ was published that shows a review of 3D-Echo optimal application in $\mathrm{CHD}$, including technical considerations, application to different injuries, the procedural guide and functional evaluation; it establishes that consistent and intuitive guidance of the $3 \mathrm{D}$ images is required, according to a better "anatomical" approach, where the heart is visualized in the same orientation as in a person in the vertical position. With this approach, superiorly positioned structures will be shown in the upper part of the image. The "surgical views" have been used to describe $3 D$ projections that are more similar to the views during surgery, where images are projected as if the patient was lying in the supine position with the main surgeon operating from the right side of the patient.

It should be taken into account that the 3D-Echo performance has to be adapted to the heart disease. Below, some applications where it has been shown to be more useful are described.

\section{Atrial septal defect}

In interatrial septum defects, complete visualization of the defect is achieved to define the type, location, 
number and morphology, measurement of the borders of the defect and distance to other structures (Fig. 2). These anatomical details are important when the treatment option is interventionist, by means of which it is possible to determine which defects are susceptible to closure or those that could represent technical difficulty due to different anatomical variants. ${ }^{10}$

Currently, different techniques are being developed that allow the creation of hybrid images or the fusion of images to simultaneously obtain time more anatomical and functional information. ${ }^{11}$ There is equipment in the market that merges $X$-ray images and real-time 2D and 3D echocardiography. This system can be used as a guide for procedures in structural heart disease, such as atrial septal defects or patent foramen ovale percutaneous closure. During the procedure, it enables the marking of structures with points or ellipses in one of the echocardiographic images; these markers appear automatically and simultaneously in the other images, by means of which there is the possibility of seeing a marked structure in all echocardiographic images and the fluoroscopy image at the same time.

\section{Congenital mitral insufficiency}

Unlike mitral alterations in adults, congenital MV disease is usually complex and affects more than one valve component depending on the embryological alteration. In these cases, the "surface" views, both from the left atrium and from the left ventricle, offer a detailed evaluation of the mobility of the leaflets and the fusion of the commissures. ${ }^{12}$ The view from the left ventricle evaluates the subvalvular apparatus, clearly defining the presence of a single papillary muscle and the insertion of all chordae tendineae in that muscle, as in parachute MV. In hammock MV, the obstruction is shown to be caused by an alteration in the mitral subvalvular apparatus and direct insertion of the leaflets in papillary muscles. From the surface view of the left atrium, the mitral supravalvular membrane, the double mitral orifice (Fig. 3) and the anterior mitral leaflet cleft can be precisely defined.

The 3D TEE approach offers better image quality due to its greater temporal and spatial resolution in relation to those obtained by $3 \mathrm{D}$ with transthoracic views. It is indicated when better anatomical definition is required and for MV analysis and quantification, as well as to determine the insufficiency mechanisms and the geometry of the regurgitant orifice. It is of special support in intraoperative assessment in order
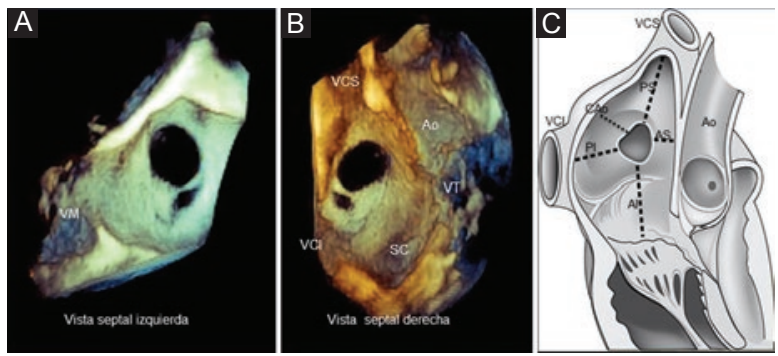

Figure 2. 3D transesophageal echocardiographic images from left $(A)$ and right $(B)$ atrial septal surface views, where an interatrial defect and its relationship with adjacent structures are observed. In the diagram $(C)$, the dotted lines mark the edges: the posterior ones are in relation to the venae cavae and the anterior ones to the aorta and the atrioventricular valves. $\mathrm{VM}=$ mitral valve, $\mathrm{VCS}=$ superior vena cava, $\mathrm{VCl}=$ inferior vena cava, $A o=$ aorta, $V T=$ tricuspid valve, $S C=$ coronary sinus .
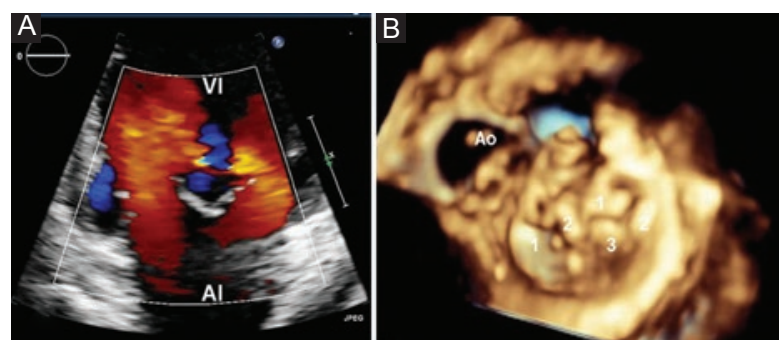

Figure 3. Two- and three-dimensional transthoracic echocardiographic images, where a double mitral orifice per central band is observed $(A)$. Notice the anatomical detail that is achieved with three-dimensional reconstruction from the atrial surface view $(B)$, where it can be confirmed that the medial orifice has two valves, while in the lateral three valves are observed, marked with numbers. $A I=$ left atrium, $V I=$ left ventricle, $A o=$ aorta.

to corroborate the anatomical lesion and define the severity of residual lesions.

\section{Double outlet right ventricle}

Double outlet right ventricle includes an extremely varied anatomical spectrum. A detailed understanding of the anatomical variants is required for correct diagnosis and for the decision of the type of surgical correction, including the location, size, relationship and distance of the ventricular septal defect to the semilunar valves, conal morphology, spatial relationship of the great arteries and associated lesions: obstructions to the output routes, abnormalities of the AV valves, ventricular hypoplasia or abnormal coronary patterns. Echocardiography plays a vital role in diagnosis: 2D-Echo has traditionally been used to plan surgical intervention, using multiple echocardiographic views, and 3D-Echo has the advantage of incorporating depth into the images, by means of which AV valves, ventricular septal defect and the large arteries can be visualized in a single projection. ${ }^{13}$ 


\section{D ventricular function}

Ventricular function assessment in CHD not only depends on the left function, in some heart diseases we are confronted with a systemic right ventricle, as in corrected transposition of large arteries or with high pressure due to pulmonary obstruction or volumetric overload (as it occurs in the tetralogy of Fallot post-operated patient of with residual pulmonary insufficiency) or even to a single ventricle physiology, and hence three-dimensional volumetric quantification for function assessment is an alternative for the study and follow-up of these patients. ${ }^{14}$

Visualization of the left ventricle by means of 3D-Echo in patients with CHD allows to analyze volumes, function and segmental analysis, as well as the study of dyssynchrony; however, even when the comparability of 3D-Echo with magnetic resonance, nuclear medicine and ventriculography has been demonstrated, there are no sufficiently extensive investigations to establish normal values ranges of these structures in pediatric patients, in addition to variations in the calculation of ventricular volumes and function due to the morphological changes of the chambers inherent to CHDs. Notwithstanding, it has been shown to be useful mainly in heart diseases where, due to the pathophysiology itself, the left ventricle modifies its anatomy.

Until recently, the utility of 3D-Echo in the measurement of right ventricular (RV) volume and ejection fraction had not been analyzed due to the complexity of its morphology, as well as to the technical difficulty for the acquisition of adequate images. Recently, the usefulness of RV volumetric measurements in comparison with magnetic resonance imaging, using the disc addition technique, has been demonstrated, using a multi-planar reconstruction protocol and automatic border detection, by means of which an excellent correlation has been identified between the measurements made by 3D-Echo and those made by magnetic resonance. In patients with univentricular hearts, 3D-Echo has been shown to obtain results that are comparable with those of magnetic resonance imaging, as well as values lower than those obtained by the latter in the calculation of volumes and ejection fraction. ${ }^{15}$ 


\title{
Evolution and results in the treatment of congenital heart diseases at global level
}

\author{
Carlos Alva-Espinosa
}

The concept of evolution comes from the Latin term evolutio and refers to the verb to evolve and its effects. In its broadest sense, evolution is a universal process that consists of change. Our planet arose and has evolved from the evolution of the universe itself, the former $\mathbf{4 6 0 0}$ million years ago, the latter is at least 13.7 billion years old. Life on Earth emerged more than 3 billion years ago and has deployed in increasingly complex and diverse forms; however, this evolutionary development had no direction, purpose or sense. Changes are the product of random contingencies before the immensity of time where natural selection has been blind. Very recently, since the appearance of man, with his awareness capable of reflecting on the past and projecting it to the future, evolution for the first time has direction. Humanity points towards a transformation of its environment and its own life to establish human progress, not without setbacks, but gradually and progressively modifying natural history. Medicine is a good example of this process. Medical interventions are measured against the natural evolution of disease, namely, with survival.

Evolution in the knowledge and treatment of $\mathrm{CHD}$ has been one of the most spectacular achievements of medicine. In the middle of the last century, children with tetralogy of Fallot hardly reached adulthood. From 1938 on, when Dr. Gross ${ }^{16}$ successfully performed the first ductus arteriosus ligature, a change in the prognosis of patients with $\mathrm{CHD}$ was initiated. Since then, and less than 80 years away, the possibility for a child with CHD who receives treatment to reach adulthood is $89 \% .{ }^{17}$ A faithful reflection of the progress in the treatment of these patients is the fact that, since 2010, there are more adults with $\mathrm{CHD}$ than children with this anomaly. Of the totality of these patients, $66 \%$ are adults. ${ }^{18} \mathrm{Be}$ low, some of the most significant changes in the results of $\mathrm{CHD}$ treatments are presented, with the fundamental purpose to update the diagnostic, therapeutic and prognostic conceptualization of this group of patients.

\section{Transposition of the great vessels (TGV)}

It is in the treatment of newborns with transposition of the great vessels (TGV) that the progress in the treatment of these lesions is clearly demonstrated. The two-dimensional echocardiogram is sufficient to establish the diagnosis (Fig. 4). TGV is a complex heart disease, where children have cyanosis with manifestations of heart failure in the first days of life and without treatment have rather high mortality: $90 \%$ of children born with TGV die within the first year of life.19 Currently, the Jatene operation or arterial switch (the operation that corrects TGV) has an operative mortality of 0 to $2.2 \%,{ }^{20}$ while 15 -year survival to $97.6 \%$, with a practically normal quality of life. ${ }^{21}$

\section{Atrial septal defect}

Atrial septal defect is one of the most common CHDs, consisting of the passage of blood from the left to the right atrium through the defect; it mainly affects girls, who are asymptomatic or have mild dyspnea and palpitations. In the 1970s, Dr. Campbell estimated mortality at $50 \%$ in its natural course. ${ }^{22}$ In 1955, when open-heart surgery was starting, Lillehei obtained a mortality rate of $33 \%$ through father/ daughter cross-circulation. ${ }^{23}$ With current surgical closure, atrial septal defect closure long-term survival is $99.6 \%,{ }^{24}$ and not only surgical results are excellent, with the advent of percutaneous intervention, atrial septal defect can be closed without extracorporeal circulation by means of a device placed in the defect by the interventional cardiologist, with a success rate of $95.7 \%$, which avoids the extracorporeal circulation pump, the pain and the healing of the surgical wound; due to these advantages, closure by catheterization is now the treatment of choice for atrial septal defect. ${ }^{25}$

\section{Tetralogy of fallot}

Tetralogy of Fallot is the most common CHD with cyanosis and one of the most extensively investigated. Its combination of defects is well known: pulmonary stenosis, ventricular septal defect, overriding aorta (over the interventricular septum) and right ventricular hypertrophy. Sometimes, catheterization is necessary to establish the diagnosis (Fig. 5). Cyanosis is the 


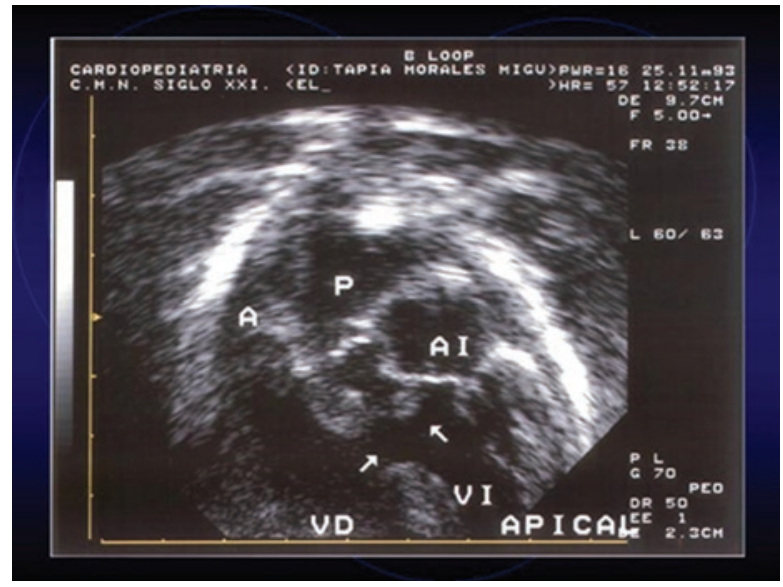

Figure 4. Echocardiogram, apical approach. Complete transposition of the great arteries. Ventricle-arterial discordances are observed: from the right ventricle $(V D)$ is the aorta $(A)$ originated, and from the left ventricle is the pulmonary $(P)$ artery born. There is sub-pulmonary ventricular septal defect (horizontal arrow) and sub-pulmonary stenosis (vertical arrow). $A I=$ left atrium, $V D=$ right ventricle, $V I=$ left ventricle.

cardinal data in diagnosis, which increases over time. In 1978, Kirklin et al. estimated that $50 \%$ of patients born with tetralogy of Fallot who are not operated die within the first years of life and hardly any survive beyond 30 years of age. ${ }^{26}$ Treatment is surgical. A better understanding of the disease, refinement in the diagnostic process and progress in technology and surgical techniques allowed to operate these children at increasingly younger ages: the recommended age for correction is at 6 months of life. Current operative mortality is $2 \%$ or lower ${ }^{27,28}$ and long-term follow-up, at 40 years, has shown a survival rate of $77.5 \%$, with practically normal quality of life in most cases. ${ }^{29}$

\section{Overall operative mortality}

There is a recent and excellent publication about surgical results of all CHDs operated from 1997 to 2015 in England, with a little more than 57 thousand operated patients. Overall operative mortality was $2.93 \%$. When the results are separated, urgent surgery mortality is $6.5 \%$; when the procedure is elective, mortality is $1.65 \%{ }^{30}$

\section{Role of interventional cardiology in the treatment of congenital heart disease}

Since the beginning of interventional cardiology in 1953 by Rubio Álvarez et al. to treat a case of pulmonary stenosis with catheterization in Mexico ${ }^{31}$ to the date of this article, the evolution and application of this technique in CHD has been exponential. Based

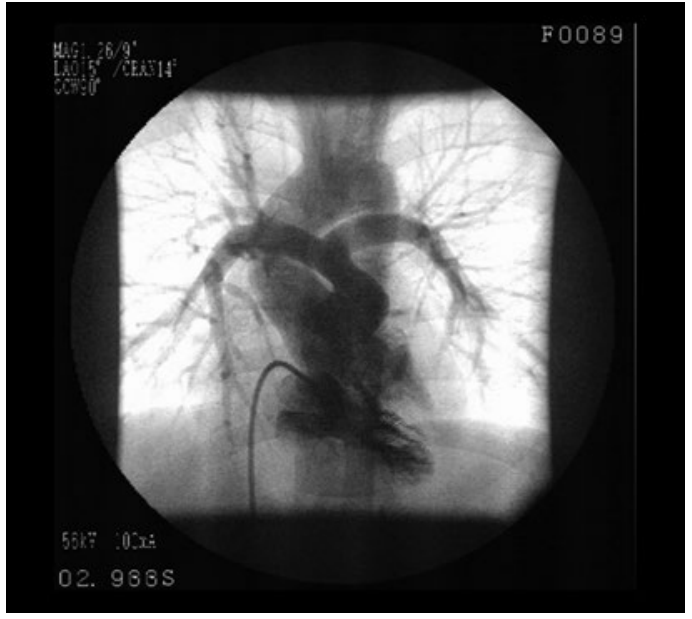

Figure 5. Right ventricle selective angiocardiogram at posteroanterior projection with $30^{\circ}$ cranial angulation of a 6-year-old child with tetralogy of Fallot. The right ventricle is observed to be hypertrophic with infundibular and valvular stenosis. The valvular ring, the trunk and branches of the pulmonary artery are of adequate caliber. There is simultaneous opacification of the aorta, moderately dilated, which delineates a right aortic arch. Patient with tetralogy of Fallot with favorable anatomy.

on an experience of 39 years, a recent outstanding article summarizes this progress: interventional catheterization as initial treatment went from 5.8 to $25.9 \%$, and as being the only treatment it went from 4.8 to $24 \%$; additionally, average age decreased from 3.4 years to 0.6 years. However, this has not meant a decrease in surgical interventions, which increased from 1717 in 1997 to 5299 in an English work. ${ }^{30}$ The explanation for the growth, both of interventional cardiology and surgery, is consistent with the increase in the number of patients and the larger availability of therapeutic options that some decades ago were not available.

\section{Prevalence of congenital heart diseases in adults}

As a consequence of the decrease in the mortality of patients with $\mathrm{CHD}$, in Canada, the prevalence in children has increased by $22 \%$, while in adults this effect has been more pronounced: prevalence rose by $85 \%$ between 1985 and 2000. ${ }^{32}$

In 2016, Gilboa et al. published the total number of patients alive with CHD in the United States: 2.4 million, out of which 1.4 million are adults. ${ }^{33}$

In Mexico, in a conservative calculation made in 2006, we estimated 300 thousand adults alive with $\mathrm{CHD}$, with an annual increase of 15 thousand cases, ${ }^{34}$ 
which indicates that by 2018 there could be nearly half a million adults with $\mathrm{CHD}$ in Mexico.

Given the significant increase in the number of patients with $\mathrm{CHD}$, developed countries have organized themselves to face the challenge of addressing the complex transition of adolescents with $\mathrm{CHD}$ and their entry into adult life. This requires a multidisciplinary team. With this challenge in mind, the Canadian Adult Congenital Heart Network was founded in 1991, with the explicit purpose of providing care to these patients, while in 1993, the Jane Somerville Foundation was founded in Europe with the same purpose, which evolved into the Grown-up Congenital Heart Disease from the European Society of Cardiology. In 1994, the Adult Congenital Heart Association and the
International Society for Adult Congenital Heart Disease were created. In those countries, the subspecialty for adult congenital heart diseases was created. In Mexico, although in the Siglo XXI National Medical Center Cardiology Hospital, in the National Institute of Cardiology and in other centers there are cardiologists dedicated to the care of these condition, there is no such subspecialty.

The growing number of patients with $\mathrm{CHD}$, which paradoxically reflects the therapeutic success over the past few decades, implies a public health challenge. It will be necessary to train more CHD specialists for children and adults in the country in order to address this growing group of patients with quality and efficiency. 


\title{
The pregnant woman with congenital heart disease
}

\author{
Lucelli Yáñez-Gutiérrez
}

The advances in the treatment of CHD have enabled patients to have a longer survival and for 9 out of each 10 to reach adulthood; approximately $50 \%$ are females and at some moment the possibility of motherhood will be raised and having a full-term pregnancy, which will be considered high-risk, will be desired.

Systemic arterial hypertension is the most common cardiac complication in pregnancy and $\mathrm{CHD}$ is the most common cardiovascular disorder. It is estimated that one out of every 156 pregnant women can be affected, as this is a group where a mortality of two per 100,000 pregnant women and an overall mortality of approximately $5 \%$ have been recorded. Consequently, heart disease is the main cause of maternal mortality during pregnancy. ${ }^{35}$ Pregnancy per se is a state that causes changes in the cardiovascular system to meet the demands of the mother and the fetus. Due maternal-fetal care is a challenge that makes the integration of multidisciplinary teams trained for the care of these patients essential.

In Mexico, the initiation of sexual life is estimated to occur approximately around 12 years of age, and it is therefore important to start early with the sensitization of parents and girls and adolescents with heart conditions in order for them to know their disease and be informed on the morbidity and mortality of the interventions they are to undergo in the future, the risk of complications when they reach adulthood, life expectancy according to the type of heart disease and the probable need of new surgeries in adulthood, the risk of inheritance, as well as the use of cardiovascular drugs that can cause fetal malformations, emphasizing on the use of oral anticoagulation and the risk of fetopathy induced by this group of drugs.

Family planning methods should be early proposed in order to promote a responsible sex life and free of risk of sexually transmitted infections or unwanted pregnancies, and together with the gynecology department, a contraceptive method that does not imply higher risk must be chosen. It is important to inform which could be the planning methods that represent the best alternatives. For example, hormone-based methods increase the risk of thromboembolic events, alter the metabolism of oral anticoagulants, fail when antibiotics have to be used and lose their effect when
Table 1. Hemodynamic changes during pregnancy

Increase in cardiac output by 30 to $50 \%$

Increase in blood volume by 18 to $25 \%$

Decrease in atrioventricular oxygen difference

Increase in myocardial contractility

Increase in heart rate by $20 \%$ (10 to 20 beats per minute)

Increase in plasma volume by 40 to $50 \%$

Decrease in systemic blood pressure

Increase in pulse pressure

Decrease in diastolic $>$ decrease in systolic

Increase in regional flow

(uterus, mammary gland, kidney, skin)

Decrease in vascular resistance

(systemic and pulmonary)

$\leftrightarrow$ Central venous pressure

$\leftrightarrow$ Wedge

Hypercoagulability

bosentan is used. The intrauterine device entails a low risk of bacteremia or infectious endocarditis and, at the moment of its placement, $5 \%$ of patients may experience a vasovagal phenomenon resulting from the manipulation of the cervix. The least recommended are the barrier methods, because of the high probability of failure. As regards definitive methods, certain intratubular implants that can be removed when pregnancy is planned can be used. ${ }^{36}$

The care of these patients should be carried out in comprehensive form, with teams made up of pediatric cardiologists, cardiologists specialized in the care of adults with $\mathrm{CHD}$, perinatal obstetrician gynecologists, as well as other specialists trained in related complications.

An important aspect to consider are the changes that physiologically modify the cardiovascular status during pregnancy: there is an increase of up to $50 \%$ in cardiac output and total blood volume, the heart rate increases and systemic blood pressure tends to decrease in the two first trimesters and respiratory changes also occur, such as a $50 \%$ increase in per-minute ventilation and approximately an increase 
Table 2. Maternal mortality according to functional class

\begin{tabular}{llr}
\hline Class & Manifestations & Mortality (\%) \\
\hline I Asymptomatic & No physical activity limitation & 2.5 \\
II Dyspnea on intense exertion & Ordinary activity produces palpitations, dyspnea or angina & $5.7-10.5$ \\
II-III Dyspnea on moderate exertion & Few physical activities & $10-19$ \\
III Dyspnea on minimal exertion & Normality only at rest; minor physical activities are impossible & $19-27$ \\
IV Dyspnea at rest & Heart failure or unstable angina & $40-50$ \\
\hline
\end{tabular}

Table 3. Patient management according to the risk

\begin{tabular}{llll}
\hline No increase & Mild increase & Moderate increase & High risk \\
\hline $\mathbf{1}$ or $\mathbf{2}$ visits to cardiologist & Visit every $\mathbf{3}$ months & Examination every $\mathbf{1}$ to $\mathbf{2}$ months & Continuous follow-up \\
\hline Not repaired & Not repaired & Not repaired & -Pregnancy termination \\
-Pulmonary stenosis & -Atrial septal defect & -Tetralogy of Fallot & -Severe pulmonary arterial hypertension \\
-Patent ductus arteriosus & -Ventricular septal defect & -Systemic right ventricle & -Left ventricle ejection fraction $<30 \%$ \\
-Prolapse of the mitral valve & & & -Functional class III-IV \\
Repaired & Repaired & Repaired & -Peripartum cardiomyopathy \\
-Atrial septal defect & -Tetralogy of Fallot & -Fontan procedure & -Severe coarctation \\
-Ventricular septal defect & & & -Marfan syndrome with aortic dilatation $>45$ mm \\
-Patent ductus arteriosus & & & -Bicuspid aortic valve with $>50$ mm dilatation \\
-Abnormal pulmonary & & \\
venous connection & & \\
\hline
\end{tabular}

of $20 \%$ in oxygen consumption, with a $40 \%$ reduction of functional residual capacity (Table 1) ${ }^{37}$ In addition, reversible structural changes occur, which may be poorly tolerated in women with heart disease, such as myocardial hypertrophy, cardiac cavities dilation, valvular insufficiency, depression of contractility and mild dilatation of the aortic root. It should be borne in mind that, during pregnancy, the pro-arrhythmic and pro-thrombotic phenomena are increased.

The challenge is twofold: both maternal and fetal risk have to be considered. Consequently, various multicenter studies have established the risk factors for maternal and fetal morbidity and mortality:

- Maternal: history of arrhythmias, use of more than 3 cardiovascular drugs, functional class prior to pregnancy, heart disease with left obstruction, severe valvular insufficiency, mechanical prosthesis (anticoagulation) and cyanosis.

- Fetal: multiple gestation, maternal history of smoking, cyanotic heart disease, presence of mechanical prosthesis and use of more than 3 cardiovascular drugs. ${ }^{38}$

The World Health Organization (WHO) stratifies the risks during pregnancy as follows:

- WHO I (maternal risk of cardiac events from 2.5 to $5 \%$ ): mild heart disease (e.g., pulmonary stenosis, patent ductus arteriosus, MV prolapse), successfully repaired cardiac defects (closure of atrial or ventricular septal defect or patent ductus arteriosus, anomalous pulmonary venous drainage) and isolated atrial or ventricular ectopic beats.

- WHO II (maternal risk of cardiac events from 5.7 to $10.5 \%$ ): unoperated atrial or ventricular septal defect, repaired tetralogy of Fallot and most arrhythmias.

- WHO II-III (maternal risk of cardiac events from 10 to $19 \%$ ): mild left ventricular impairment, hypertrophic cardiomyopathy, other valvular heart diseases, Marfan syndrome without aortic dilatation, repaired aortic coarctation

- WHO III (maternal risk of cardiac events from 19 to $27 \%$ ): mechanical valve, systemic right ventricle and Fontan circulation.

- WHO IV (maternal risk of cardiac events from 40 to $100 \%$ ): pulmonary arterial hypertension of any cause, severe systemic ventricular dysfunction (LVEF $<30 \%$ ), previous peripartum cardiomyopathy, severe left stenosis (mitral or aortic), Marfan syndrome with aorta dilated (>45 mm) or dilatation greater than $50 \mathrm{~mm}$ in bicuspid aortic valve, severe aortic coarctation ${ }^{5}$ (Table 2).

When considering to subject the pregnant woman to labor, hemodynamic changes that occur because 
of pain and anxiety should not be forgotten, as well as that with each uterine contraction the heart rate and cardiac output increase by $50 \%$, i.e., 300 to $400 \mathrm{~mL}$ more, and that cardiac output increases at the moment the inferior vena cava is decompressed due to the transfer of blood from the contracted uterus; therefore it cannot be considered as an option in patients with unresolved or residual shunting (e.g., extensive atrial septal defect or patent ductus arteriosus) and, in some cases, cesarean section with prophylaxis for endocarditis and adequate management of blood volume and ventilation should be proposed. Based on these studies, the follow-up of these patients and how pregnancy is to be brought to full term should be defined (Table 3).

Some therapeutic procedures will be able to be carried out with relative safety, such as imaging (X-rays, CT scans or angiographies) or interventional studies (angioplasties and valvuloplasties), conversely to cardiac surgery, since cardiopulmonary bypass compromises fetal viability and the risk of fetal loss is $30 \% .^{39}$

The most relevant aspects regarding the pregnant woman with CHD can be summarized as follows:

- Knowing the physiological hemodynamic changes occurring during pregnancy facilitates the detection of complications in the context of women who have CHD.

- Maternal or fetal risk is directly related to the type of heart disease, the type of surgical repair or late complications inherent to heart disease.

- The care of pregnant women who have CHD should be provided by a multidisciplinary team.

- It is the obligation of the pediatric cardiologist and the cardiologist expert in CHD to guide women with heart disease who face the decision of pregnancy, which with good management can be brought to a successful outcome. 


\title{
The reality of congenital heart diseases in Mexico
}

\author{
Horacio Márquez-González
}

There is no greater uncertainty than ignorance of the problem, which can be applied to the $\mathrm{CHD}$ issue in Mexico. Every year, we expect 15,000 to 18,000 neonates to have a cardiac malformation; however, this is an estimate based on the incidence in other countries extrapolated to the number of annual births in Mexico. Actually, our information system cannot specify basic epidemiological units such as frequency, incidence and prevalence of CHD in children and adults either nationally or by state.

Centralization of hospitals delays and limits the access to resources. Until 2009, in our country there were 9 centers certified for the care of $\mathrm{CHD}$ ( 7 in Mexico City), with the additional characteristic that their tasks were exclusively specialized in the pediatric or cardiologic areas, and thus, upon reaching legal age, mandatory referral to other hospitals was necessary. ${ }^{40}$ In this interval, factors such as the type of affiliation to a particular area of the health sector, the time elapsed for the first consultation at the new hospital and availability of the economic resources were responsible for the process of care to be interrupted. However, new hospitals that are expected to reach the specialization curve in the next decade are currently operating.

Another reality is that there is a delay in early detection. Although $\mathrm{CHD}$ fetal diagnosis currently can be established by gynecologists who have postgraduate training in maternal-fetal health, there is still not an adequate distribution of these professionals in the places where the screening work should be done; in addition, the misuse of ultrasound in the hands of untrained professionals makes for direction and opportunity of diagnosis to be diminished.

It's also a reality that the clinical pediatrician is not fully skilled and needs interaction with the pediatric cardiologist, who usually does not perform his/her duties at secondary care, and thus the process of reference can represent a real difficulty for care in some states.

\section{Liaison clinics}

Transition or liaison clinics are a reality in some countries that establish the minimum of competences (ensured by courses with university endorsement of no less than one year duration) the clinical cardiologist and the pediatric cardiologist must acquire to ensure that the liaison is properly completed and to allow follow-up by a medical professional who orchestrates the coverage of the needs in future stages of life.

\section{Adults with CHD in Mexico}

In Mexico there are only few hospitals with a CHD liaison clinic that can provide information on the current state of the patient with cardiac disease at the adult stage. In the Cardiology Hospital of the Siglo XXI National Medical Center of the Mexican Institute of Social Security, there is one of these clinics. In 2017, it published a 5-year series of cases. ${ }^{41}$ As regards adult population, out of 3483 patients with confirmed CHD, $25.6 \%$ were diagnosed in adulthood and the three main conditions were atrial and ventricular septal defect, and patent ductus arteriosus. This hospital center has the peculiarity of being a tertiary care center and covers the center and southwest areas of the population affiliated to the Mexican Institute of Social Security in the country. The analysis by states showed that, in Chiapas, the CHD diagnosis was established during adulthood in $33 \%$ of patients, in Oaxaca, in $19 \%$ and in Guerrero, in $17 \%$. As for adult woman with $\mathrm{CHD}, 18 \%$ were diagnosed at their first pregnancy and $17 \%$ already knew they were carriers of this malformation, in spite which they got pregnant without any strategy for family planning or for the resolution of pregnancy. These data should be considered to be alarming, especially with regard to maternal and early childhood mortality, owing to the already known association between the mother with $\mathrm{CHD}$ and prematurity or asphyxiation of the fetus in $50 \%$ of cases.

Results of the state of Chiapas were also published, based on data reported in the 2015 Intercensal Survey. ${ }^{42}$ Total population of the state was $5,217,908$ inhabitants $(2,681,187$ women), out of which 626,148 affiliates $(12.4 \%)$ were affiliated to the ordinary regime of the Mexican Institute of Social Security. One in every 2000 adults was found to have an undiagnosed CHD, 1.8 out of every 2000 affiliated women of childbearing age had a CHD and were not aware of it, which means that one out of every 10 complicated pregnancies may be associated with this cause. 


\section{Conclusions}

1. Echocardiography is the most useful and practical diagnostic tool in CHD. Advances with the three-dimensional, transthoracic and transesophageal modality provide additional benefits in the diagnosis of CHDs, both in their structure and function and in the planning of treatment and transoperative evaluation.

2. In the treatment of CHD, operative and long-term mortality have significantly decreased. Currently, $89 \%$ of patients reach adulthood. Of the totality of patients, two thirds are adults.

3. The role of interventional cardiology is increasingly important; however, the number of patients who require surgery is also increasing.

4. Women of childbearing age with CHD should have a birth control plan and a risk assessment for when they decide to become pregnant.

5. Structural and functional changes occur during pregnancy, which implies an additional challenge, both for the woman with CHD and for the fetus.

6. Adequate care of the pregnant woman with $\mathrm{CHD}$ requires the work of a multidisciplinary team.

7. In Mexico, it is important for the real incidence, prevalence and frequency of CHD both in children and adults to be known, through a national registry system that allows to objectively identify the problem.

8. Training of clinical, surgical and interventional specialists in pediatric and adult CHD is necessary in order to respond to the growing demand for care of these patients.

\section{References}

1. Del Pasqua A, Sanders SP, De Zorzi A, Toscano A, Lacobelli R, Pierli C et al. Impact of three-dimensional echocardiography in complex congenital heart defect cases: the surgical view. Pediatr Cardiol. 2009; 30:293-300.

2. Jenkins C, Monaghan M, Shirali G, Guraraja R, Marwick TH. An intensive interactive course for 3D echocardiography: is "crop till you drop" an effective learning strategy? Eur J Echocardiogr. 2008;9:373-380.

3. Srivastava S, Printz BF, Geva T, Shirali GS, Weinberg PM, Wong PC, et al. Task force 2: pediatric cardiology fellowship training in noninvasive cardiac imaging: endorsed by the American Society of Echocardiography and the Society of Pediatric Echocardiography. J Am Soc Echocardiogr. 2015;66:687-698.

4. Von Ramm OT, Smith SW. Real time volumetric ultrasound imaging system. J Digit Imaging. 1990;3:261-266.

5. Vargas-Barrón J, Romero-Cárdenas A, Espínola N, Roldán Gómez FJ, Vázquez-Antona CA, Attie $\mathrm{F}$, et al. Three-dimensional echocardiography in adult congenital heart disease. En: Nanda NC, Sorrell VL, editors. Atlas of three-dimensional echocardiography. EE. UU.: Futura Publishing; 2002.

6. Vázquez-Antona CA, Muñoz L, Erdmenger J, Roldán J, Vargas J. Ecocardiografía tridimensional en la evaluación de los defectos cardiacos congénitos. Portuguese J Card. 2004;23:60.
7. Vázquez-Antona, CA. Ecocardiografía tridimensional en cardiopatías congénitas. En: Martínez-Ríos MA, Damas De Los Santos F, Lorenzo-Negrete JA, editores. Contribuciones del Instituto Nacional de Cardiología Ignacio Chávez. México: Permanyer; 2014.

8. De Castro S, Caselli S, Papetti F, Ventriglia F, Giardina A, Cavaretta E, et al: Feasibility and clinical impact of live three-dimensional echocardiography in the management of congenital heart disease. Echocardiography. 2006;23:553-556.

9. Simpson J, Lopez L, Acar P, Friedberg M, Khoo N, Ko H, et al. Three-dimensional echocardiography in congenital heart disease: an expert consensus document from the European Association of Cardiovascular Imaging and the American Society of Echocardiography. Eur Heart $\mathrm{J}$ Cardiovasc Imaging. 2016;17:1071-1097.

10. Roldán FJ, Vargas-Barrón J, Vázquez-Antona CA, Castellanos LM, Erdmenger-Orellana J, Romero-Cárdenas A, et al. Three dimensional transesophageal echocardiography of atrial septal defects. Cardiovasc Ultrasound. 2008:6:38

11. Balzer J, Van-Hall S, Böring YC, Kelm M. New role of echocardiography in the Cath Lab: novel approaches of peri-interventional 3D echocardiography. Curr Cardiovasc Imaging Rep. 2013;6:445-453.

12. Kutty S, Colen TM, Smallhorn JF. Three-dimensional echocardiography in the assessment of congenital mitral valve disease. J Am Soc Echocardiogr. 2014;27:142-154.

13. Pushparajah K, Barlow A, Tran VH, Miller OI, Zidere V, Vaidyanathan B, et al. A systematic three-dimensional echocardiographic approach to assist surgical planning in double outlet right ventricle. Echocardiography. 2013;30:234-238.

14. Renella P, Marx GR, Zhou J, Gauvreau K, Geva T. Feasibility and reproducibility of three-dimensional echocardiographic assessment of right ventricular size and function in pediatric patients. J Am Soc Echocardiogr. 2014;27:903-910.

15. Jurcut R, Giusca S, La-Gerche A, Vasile S, Ginhina C, Voigt JU. The echocardiographic assessment of the right ventricle: what to do in 2010? Eur J Echocardiogr. 2010:11:81-96

16. Gross RE, Hubbard JP. Surgical ligation of patent ductus arteriosus. Report of first successful case. JAMA. 1939;112:129.

17. Moons P, Bovijn L, Budts W, Belmans A, Gewillig M. Temporal trends in survival to adulthood among patients born with congenital heart disease from 1970 to 1992 in Belgium. Circulation. 2010;122:2264-2272.

18. Marelli AJ, Ionescu-Ittu R, Mackie AS, Guo L, Dendukuri N, Kaouache M. Lifetime prevalence of congenital heart disease in the general population from 2000 to 2010. Circulation. 2014;130:749-756.

19. Liebman J, Cullum L, Belloc NB. Natural history of transposition of the great arteries. Circulation. 1969;40:237-262.

20. Frazer C. Resultados de switch para TGV. Semin Thorac Cardiovasc Surg Pediatr Card Surg Annu. 2017;20:38-42.

21. Shim MS, Jun TG, Yang JH, Park PW, Kang IS, Huh J, et al. Current expectations of the arterial switch operation in a small volume center: a 20-year, single-center experience. Cardiothorac Surg. 2016;11:34.

22. Campbell M. Natural history of atrial septal defect. $\mathrm{Br}$ Heart J. 1970;32:820-835.

23. Lillehei $\mathrm{CW}$, Cohen $\mathrm{M}$, Warden HE, Varco RL. The direct vision intracardiac correction of congenital anomalies by controlled cross circulation; results in thirty-two patients with ventricular septal defects, tetralogy of Fallot, and atrioventricularis communis defects. Surgery. 1955;38:11-29.

24. Téllez-De Peralta G. Historia de la cirugía cardiovascular. En: Tratado de cirugía cardiovascular. España: Sociedad Española de Cardiología; 1999.

25. Moore JW, Vincent RN, Beekman RH, Benson L, Bergersen L, Holzer R, et al. Procedural results and safety of common interventional procedures in congenital heart disease: initial report from the National Cardiovascular Data Registry. J Am Coll Cardiol. 2014:64:2439-2451.

26. Bertranou EG, Blackstone EH, Hazelrig JB, Turner ME, Kirklin JW. Life expectancy without surgery in tetralogy of Fallot. Am J Cardiol. 1978; 42:458-466.

27. Caruana M, Grech V. A first population-based long-term outcome study in adults with repaired tetralogy of Fallot in Malta. Congenit Heart Dis. 2017;12:301-308.

28. Starr JP. Tetralogy of Fallot: yesterday and today. World J Surg. 2010;34:658-668.

29. Cuypers JA, Menting ME, Konings EE, Opić P, Utens EM, Helbing WA, et al. Unnatural history of tetralogy of Fallot: prospective follow-up of 40 years after surgical correction. Circulation. 2014:130:1944-1953.

30. Kempny A, Dimopoulos K, Uebing A, Diller GP, Rosendahl U, Belitsis G, et al. Outcome of cardiac surgery in patients with congenital heart disease in England between 1997 and 2015. PLoS One. 2017:12:e0178963.

31. Rubio-Álvarez V, Limón RL. Valvulotomía intracardiaca por medio de un catéter. Arch Inst Cardiol Mex. 1953;23:183-192. 
32. Marelli AJ, Therrien J, Mackie AS, lonescu-Ittu R, Pilote L. Planning the specialized care of adult congenital heart disease patients: from numbers to guidelines; an epidemiologic approach. Am Heart J. 2009;157:1-8.

33. Gilboa SM, Devine OJ, Kucik JE, Oster ME, Riehle-Colarusso T, Nembhard WN, et al. Congenital heart defects in the United States: estimating the magnitude of the affected population in 2010. Circulation. 2016;134:101-109.

34. Alva-Espinosa C. Ante el adulto con cardiopatía congénita. Arch Cardiol Mex. 2006;76:57-61.

35. Knight M, Nair M, Tuffnell D. Saving lives, improving mothers' care EE. UU.: University of Oxford; 2016.

36. Canobbio MM, Perloff J, Rapkin AJ. Gynecological health of females with congenial heart disease. Int J Cardiol. 2005;98:379-387.

37 Uebing A, Steer P, Yentis S, Gatzoulis M. Pregnancy and congenital heart disease. BMJ. 2006;332:401-406.

38. Van Hagen I, Boersma E, Johnson M. Global cardiac risk assessment in the registry of pregnancy and cardiac disease: Results of a registry from the European Society of Cardiology. Eur J Heart Fail. 2016;18:523-533.
39. Regitz-Zagrosek V, Roos-Hesselink JW, Bauersachs J, Blomström-Lundqvist C, Cífková R. De Bonis M, et al. 2018 ESC Guidelines for the management of cardiovascular diseases during pregnancy. Eur Heart J. 2018;39(34): 3165-3241.

40. Calderón-Colmenero J, De La Llata M, Vizcaíno A, Ramírez-Marroquín $\mathrm{S}$, Bolio-Cerdán $\mathrm{A}$, Alva $\mathrm{C}$, et al. Medical and surgical health care for congenital heart disease: a panoramic vision of the reality in Mexico. Inquiry 2009. Rev Invest Clin. 2011;63;344-352.

41. Márquez-González H, Yáñez-Gutiérrez L, Rivera-May JL, López-Gallegos D, Almeida-Gutiérrez E. Demographic analysis of a congenital heart disease clinic of the Mexican Institute of Social Security, with special interest in the adult. Arch Cardiol Mex. 2017; pii:S1405-9940.

42. Instituto Nacional de Estadística y Geografía. Principales resultados de la Encuesta Intercensal 2015. Estados Unidos Mexicanos. México: INEGl; 2015. Disponible en: http://internet.contenidos.inegi.org.mx/contenidos/productos/prod_serv/contenidos/espanol/bvinegi/productos/nueva_ estruc/702825078966.pdf 